\title{
PulmoCor: national registry for pulmonary hypertension
}

\author{
M. C. Post • A. P. Van Dijk · E. S. Hoendermis · H. J. Bogaard • V. Van Empel • K. A. Boomars
}

Published online: 5 April 2016

(c) The Author(s) 2016. This article is available at SpringerLink with Open Access

Pulmonary hypertension (PH) is a condition that refers to a mean pulmonary artery pressure of at least $25 \mathrm{mmHg}$ measured by right heart catheterisation at rest. $\mathrm{PH}$ is classified in five groups based on the underlying clinical condition [1]. Some of these conditions are orphan diseases and managed in designed tertiary $\mathrm{PH}$ centres with dedicated multidisciplinary teams. During the last decades great progress has been made on the epidemiology, aetiology, pathophysiology and treatment of PH. Some of these efforts were mainly based on national $\mathrm{PH}$ registries, first published in the early $1980 \mathrm{~s}$ [2]. The primary goal of these clinical observational $\mathrm{PH}$ registries is to describe patients with $\mathrm{PH}$ and the impact of this disease [3]. Until recently, no such a national $\mathrm{PH}$ registry was available in the Netherlands.

M. C. Post $(\bowtie)$

Department of Cardiology, St. Antonius Hospital

Nieuwegein, the Netherlands

e-mail: m.post@antoniusziekenhuis.nl

A. P. Van Dijk

Department of Cardiology, Radboud University Medical Center

Nijmegen, the Netherlands

E. S. Hoendermis

Department of Cardiology, University Medical Center Groningen

Groningen, the Netherlands

H. J. Bogaard

Department of Pulmonary Diseases, VU University Medical

Center

Amsterdam, the Netherlands

V. Van Empel

Department of Cardiology, Maastricht University Medical Center

Maastricht, the Netherlands

K. A. Boomars

Department of Respiratory Medicine, Erasmus Medical Center

Rotterdam, the Netherlands
In 2012, the Dutch multidisciplinary multicentre registry for PH (PulmoCor) was initiated by three tertiary PH centres and supported by the Interuniversity Cardiology Institute of the Netherlands (ICIN). Nowadays, six tertiary $\mathrm{PH}$ centres participate in this program (5 university medical centres and 1 non-university hospital). A working group including PH specialists (both cardiologists and pulmonologists) of all participating centres was established and regulations for this project have been drawn up. Several privacyenhancing technologies have been used in accordance with the Dutch Privacy protections laws for data collection.

The aims of the PulmoCor registry are to further optimise patient care and research in the field of $\mathrm{PH}$, and the joint collaboration between the national and international $\mathrm{PH}$ centres. Interestingly, the same structured webbased PH database, specially developed for the management of PH patients (PAHtool, Inovolutus, Portugal), is used in other international $\mathrm{PH}$ centres as well, both European and non-European [4]. The PulmoCor registry will facilitate investigation of the epidemiology of specific subtypes of $\mathrm{PH}$, the treatment and long-term outcome. It will increase the awareness of this rare disease throughout the Netherlands. Furthermore, the registry can be used as clinical database as well.

Based on the current international guidelines, all PH centres used a standardised diagnostic approach for $\mathrm{PH}$ analysis [1]. Different data regarding the initial work-up and followup could be included in the PulmoCor registry. Each participating $\mathrm{PH}$ centre is using the secured uniformly structured database for the registration of their patients and these data are only accessible by this centre. To date, a total of 1493 patients with pulmonary hypertension (both prevalent and incident cases) have been included in the PulmoCor registry. In Fig. 1, this total group is shown according to the 


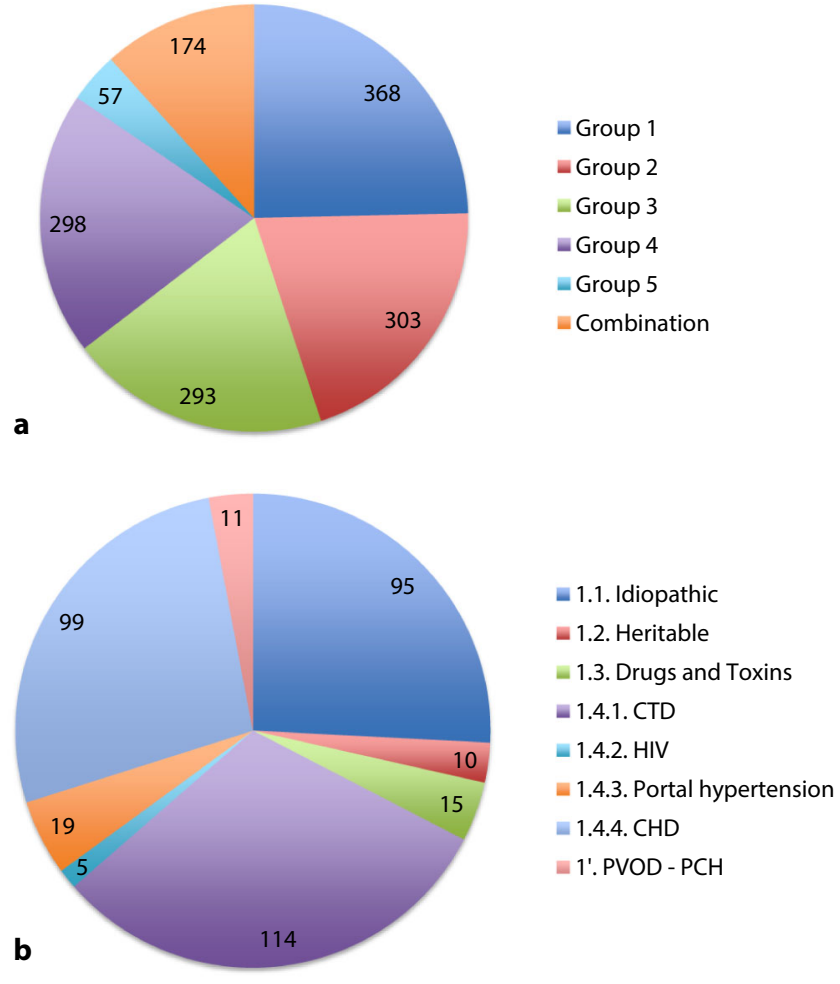

Fig. 1 Total number of patients with pulmonary hypertension included in the PulmoCor registry divided by clinical classification (a) and the subgroup of pulmonary arterial hypertension (b). Group 1 Pulmonary arterial hypertension; Group $2 \mathrm{PH}$ due to left heart disease; Group $3 \mathrm{PH}$ due to lung disease and/or hypoxia; Group 4 Chronic thromboembolic $\mathrm{PH}$ and other pulmonary artery obstructions; Group $5 \mathrm{PH}$ with unclear and/or multifactorial mechanisms [1]. (CTD connective tissue disease, HIV human immunodeficiency virus, $C H D$ congenital heart disease, $P V O D$ pulmonary veno-occlusive disease, $P C H$ pulmonary capillary haemangiomatosis) clinical classification (a) and the subgroup of patients with pulmonary arterial hypertension (PAH), group $1(\mathbf{b})$.

The uniformly designed PulmoCor registry data acquisition will increase the value of national collaboration both clinically and scientifically.

Open Access This article is distributed under the terms of the Creative Commons Attribution 4.0 International License (http:// creativecommons.org/licenses/by/4.0/), which permits unrestricted use, distribution, and reproduction in any medium, provided you give appropriate credit to the original author(s) and the source, provide a link to the Creative Commons license, and indicate if changes were made.

\section{References}

1. Galiè N, Humbert M, Vachiery J-L, et al. ESC/ERS Guidelines for the diagnosis and treatment of pulmonary hypertension. Eur Resp J. 2015;46:903-975.

2. Awdish R, Definition CH. epidemiology and registries of pulmonary hypertension. Heart Fail Rev. 2015. doi:10.1007/s10741015-9510-y.

3. McGoon MD, Benza RL, Escribano-Subias P, et al. Pulmonary arterial hypertension: epidemiology and registries. J Am Coll Cardiol. 2013;62:D51-D59.

4. Baptiste R, Meireles J, Agapito A, et al. Pulmonary hypertension in Portugal: first data from a nationwide registry. Biomed Res Int. 2013. doi: $10.1155 / 2013 / 489574$. 


\section{Advertisement placed here.}

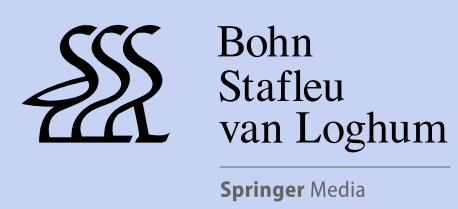

Houten 2016 


\section{Advertisement placed here.}

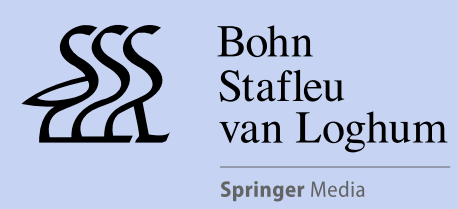

Houten 2016 


\section{Advertisement placed here.}

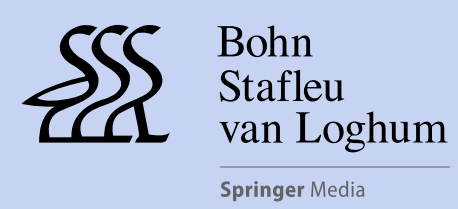

Houten 2016 


\section{Advertisement placed here.}

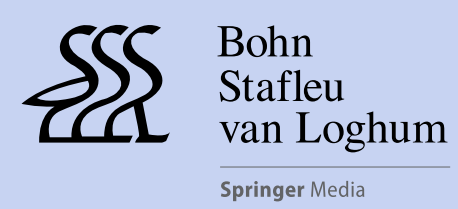

Houten 2016 